\title{
Assessing hydrological changes in wetland areas of the Arctic and Subarctic based on microwave remote sensing data
}

\author{
Andrey N. Romanov ${ }^{1 *}$, Ilya V. Khvostov ${ }^{1}$, Vasiliy V. Tikhonov' ${ }^{2,1}$, and Evgeniy A. Sharkov ${ }^{2}$ \\ 1 Institute for Water and Environmental Problems SB RAS, romanov_alt@mail.ru \\ 2 Space Research Institute RAS, Moscow, vtikhonov@asp.iki.rssi.ru \\ * Correspondence: romanov_alt@mail.ru;
}

\begin{abstract}
Specific emissivity features of swamps and wetlands of Western Siberia were studied for changing seasonal conditions with the use of daily data of satellite microwave sounding. The research technique involved the analysis of brightness temperatures of the underlying surface at the test sites. Variations in seasonal dynamics of brightness temperatures were mainly caused by different rates of seasonal freezing of the upper waterlogged layer of the underlying surface and dielectric characteristics of water containing natural media (water body, soil, vegetation). We analyzed long-term trends in seasonal and annual dynamics of brightness temperatures of the underlying surface and estimated hydrological changes in the Arctic and Subarctic. The findings open up new possibilities for using satellite data in the microwave range for studying natural seasonal dynamic processes and predicting hazardous hydrological phenomena.
\end{abstract}

Keywords: hydrological changes, wetlands, Arctic, Subarctic, microwave remote sensing

\section{Introduction}

Swamps and wetlands, which occupy about $6 \%$ of the Earth surface, drastically affect the global water cycle, climate dynamics and carbon sequestration. Among different-type landscapes, swamps are most vulnerable ones. Their sensitivity to current shifts in global rainfall and temperature patterns, including the ability to produce large quantities of methane, are crucial for global changes.

The world's largest West Siberian Lowland is characterized by numerous wetlands located in three natural zones (tundra, taiga and forest-steppe). According to various estimates, they occupy the area of 800 th- $1 \mathrm{mln} \mathrm{km}^{2}$. The richest reserves of oil, gas and peat make the West Siberian Lowland the leading Russian region in extraction of fuel and energy resources. In recent decades, the territory of the West Siberian Lowland undergoes hydrological changes of different intensity as a result of climate change, multidirectional processes of swamp formation/drying out of wetlands and aridization. Especially noticeable hydrological changes, contributing to the occurrence of dangerous natural phenomena, are observed in the Arctic and Subarctic zones of Western Siberia. It may be associated with the combined influence of natural and anthropogenic factors such as a reduction in the perennial ice area, intensive melting of glaciers, a decrease in the number and total area of thermokarst lakes, earlier thawing and later freezing of the tundra [1], and seasonal redistribution of atmospheric precipitation [2]. The ongoing changes activate the processes of degradation of permafrost and tundra vegetation [3], intensively warm the tundra surface in deflation areas, increase evaporation rates and release additional amounts of water vapor and methane into the atmosphere thus aggravating the greenhouse effect [4].

Launching of artificial satellites equipped with microwave radiometers enabled to obtain daily data regardless of meteorological conditions, to study seasonal dynamics of hydrological changes worldwide, to calculate long-term trends of these change and to forecast the probability of occurrence of natural hazards and natural disasters [5]. Mi- 
crowave remote monitoring of hydrological changes is feasible under thorough studies of regularities and features of seasonal dynamics of brightness temperatures of the underlying surface and at the grounded choice of objective radiophysical criteria. Satellite data are used for remote determination of soil moisture [6], water temperature and salinity [7] as well as concentrations and rates of sea ice melting [8]. For remote monitoring of wetlands, satellite data from synthetic aperture radars (SAR) installed on RADARSAT-1, RADARSAT-2 and other satellites are widely used [9].

The ability of microwave radiation to penetrate vegetation layer allows to detect flooded areas. To estimate their parameters, RADARSAT-2 InSAR different-time data are employed for classifying swamps and estimating their annual changes. In the coming years, the European Sentinel SAR and Canadian RADARSAT Constellation Mission (RCM) satellite systems will provide prompt re-survey of the territory and standard modes of data collection resulting in expanded operational use of SAR data for remote monitoring of wetlands and detecting open water sites [10].

However, problems of SAR application to wetland mapping in terms of selection of proper SAR characteristics (incidence angle, frequency and polarization) still exist. Recent trends are towards application of multi-temporal, multi-frequency and multi-angle SAR images distinguished by better classification accuracy compared to single-channel configurations. The employment of cloud computing platforms (Google Earth, Engine, NASA Earth Exchange, Amazon'sWeb Services) designed to monitor wetlands on a global scale is expanding. Such platforms can simplify the analysis and management of vast data on Earth surface observations at the national and regional scales [11, 12].

In [13], the possibilities of SAR data use in characterizing wetlands and monitoring changes in water levels along the coast of the Great Lakes (USA, Canada) were investigated. The InSAR analysis made with the use of Radarsat-2 and Sentinel-1 data (2016-2018) showed that backscatter coefficients depended on water levels, vegetation height and type, including plant phenology. A temporal interpolation method was proposed in [14]. It allows the application of SAR images obtained in different periods. In 2016, seasonal dynamics of the varying area $\left(1134 \mathrm{~km}^{2}\right)$ of Lake Dongting, China (with its maximum $\left(2465 \mathrm{~km}^{2}\right)$ in July and its minimum $\left(1331 \mathrm{~km}^{2}\right)$ in October) was studied based on Sentinel-1 SAR data [15].

The findings of experimental studies suggest that integration of satellite data from several sensors is most effective for monitoring coastal wetlands [16]. The combination of optical and radar remote sensing data may be especially valuable when swamps and peat bog forests are the region of high cloudiness that limits the use of optical data. Though SAR data can "see through" clouds, they are poor in distinguishing certain types of a land cover. At present, there are various approaches to sharing optical and radar data. In [17], mapping of peat rainforests deforestation (cutting down) was based on the use of Sentinel-1 and Sentinel-2 data by the example of extended peat bogs in Southeast Asia. The accuracy of cartographic methods using only optical data versus those based on optical data supplemented with SAR data was estimated. The obtained results demonstrate that data fusion significantly improves mapping of peat swamp forests loss in Southeast Asia in contrast to application of solely radar data.

The researchers $[18,19]$ used Landsat TM satellite data combined with GIS in order to study dynamics of drying up of the Ruoergai bog located on the eastern edge of the Qinghai-Tibet plateau in western China. They found out that intensive bog drying up was induced both by natural and anthropogenic factors.

Another study [20] presents the study results of the Biebrz Wetlands located in the northeastern part of Poland. In the European Union, it is one of the largest territories formed by swamps and marshes. The investigators mapped vegetation in detail with the use of satellite data ERS-2.SAR, ENVISAT ASAR on vertical and horizontal polarizations. Soil moisture, evapotranspiration, leaf area index, wet and dry biomass, groundwater level and meteorological parameters were measured in situ. The microwave and optical data from Landsat ETM +, SPOT VEGETATION, ERS-2.ATSR satellites were measured simultaneously. Vegetation indices were calculated from satellite data in several spectral 
ranges. Changes in humidity of the area were assessed using SAR data collected in the same period of the year, but with an interval of 5 years.

By the example of swamps of the Western Boreal Plain in Alberta province (Canada), five types of land, i.e. swamps, flat peat bogs and peatlands, mineral bogs and hills with different stands of trees, height over 10 meters, depth of groundwater, chemical composition of water, $\mathrm{pH}$, electrical conductivity were identified using satellite data and geographic information systems (GIS) [21]. Satellite data processing was carried out using advanced deep learning software tools, developed tree-like classification algorithms and convolutional neural networks [22].

MODIS data from a spectroradiometer with a medium resolution were used for mapping wetlands. In [23], a method based on the analysis of multisensor images with an improved vegetation index (EVI) and used to map landscape types resting on their phenological differences was proposed. Flooded areas in the Congo Basin (Central Africa) were mapped in different seasons of the year using L-Band Synthetic Aperture Radar (PALSAR) imagery. The generalized model was improved by adding elevation data as well as mean vegetation heights from LIDAR data. These studies resulted in a detailed map of spatial distribution of four types of forest wetlands. It also followed from the satellite data analysis that estimation accuracy of flooding periods largely depended on vegetation phenology of the region.

The Extended Vegetation Index (EVI) calculated from MODIS data (2000 - 2018) was employed in detecting and mapping coastal floodplain swamps of the Gulf of Mexico, Florida, which are an important part of coastal wetlands endangered as a result of accelerated sea level rise and saltwater intrusion. The findings prove that remote sensing data can be used in detecting differences in floodplain bog vegetation associated with long-term salt water intrusion [24].

According to [25], hydrological changes occurred in 1942-2007 at the Caroni Swamp - the largest wetland in Trinidat and Tobago, were studied with the use of remote sensing technologies, GIS and extensive field research. Landscape maps were compiled for 1942, 1957, 1986, 1994, 2003 and 2007 due to aerial and high-resolution satellite imagery. The hydrology of the Caroni Swamp was changed in the 1920s to facilitate rice cultivation followed by the formation of vast areas of freshwater bogs in the region. From 1942 to 1957, the number of freshwater marshes and agricultural lands increased, but later their area steadily declined because fresh water was diverted from the wetlands and salt water penetrated further inland. The area of mangrove forests also expanded thus displacing marsh vegetation and causing a shift in wetland plant communities.

Seasonal variations in wetlands of Uliangsuhai (Autonomous Region of Inner Mongolia, China) were studied using Landsat TM / ETM data and field surveys. Based on the research results, six types of the underlying wetland surface were identified, i.e. the areas of open water, dense algae, reed, swamp, shallow and artificial reed. The estimate accuracy strongly depended on vegetation phenology [26]. In [27], aerial laser scanning was used to detect the boundaries of raised bogs in the coastal forests of eastern Australia, while remote sensing in the optical range- to describe plant communities. Changes in community composition (2006 -2007) were also assessed. The bogs boundaries precisely located along the ecotone of trees bordering the bogs. This is a hallmark of short-term and long-term monitoring. Wet and dry heathlands were well - classified due to satellite imagery and correlated with perennial plant communities identified from field studies. It was found that spatial-temporal changes in vegetation depended on phenological features of vegetation cover, but not on plant community compositions. Since the proportion of vegetation free areas was less variable, the increase in their area could be a reliable indicator for remote monitoring of changes in wetlands exposed to natural and anthropogenic impacts. Here, radiometric methods of passive microwave sounding were employed for remote monitoring of wetlands to a lesser extent than SAR.

Another study reports on physical principles of passive microwave remote sensing of hydrological variables using ground-based, on board and space microwave radiometers operating at different frequencies [28]. Radiometric data can be used for assessing 
soil moisture and vegetation biomass as well as in calculating the water surface area during seasonal flooding of bogs. Assessment of hydrological variables by microwave data is based on the use of models where emissivity relates to one or more physical characteristics of the underlying surface. Ambiguity between emissivity characteristics of the underlying surface and a particular hydrological variable leads to uncertainty in estimating the latter. Despite this limitation, daily passive microwave observations are valuable for regional and global hydrology.

One more challenging problem of remote wetlands monitoring relates with the hard-to-consider shielding effect of woody vegetation that reduces the accuracy of radiometric measurements when identifying the areas of flooded forests and wetlands with dense vegetation [29].

In [30], a technique for global mapping of surface waters with a $25 \mathrm{~km}$ resolution using daily satellite data of active-passive microwave remote sensing is described. The resulting product, known as SWAMPS, demonstrates the dependence of the underlying surface emissivity on open water sites and wetlands, including shielding vegetation. For forests or developed vegetation cover, the accuracy of detecting such areas significantly deteriorates. Seasonal variations in wetland areas and their interannual variability in northern latitudes were studied at frequencies of 19 and $37 \mathrm{GHz}$ by means of a passive microwave thermal imager (SSM / I). According to satellite data, the area of wetlands in North America $\left(48-68^{\circ} \mathrm{N}\right)$ was maximum during July- September, whereas in Northern Eurasia - from June to September. The microwave method for satellite mapping of wetland areas developed in [31] made it possible to study their long-term seasonal dynamics, depending on the duration of a snow period and the water content of a snow cover.

In this paper, a comparative analysis of seasonal and long-term changes in wetlands of the Russian Arctic and Subarctic, including the largest world wetlands is performed based on the use of SMOS daily data. Test sites (swamps, wetlands) located on the territory of Western Siberia in different natural zones (tundra, forest-tundra, taiga) under different climatic conditions were selected as main study objects.

\section{Materials and Methods}

In order to analyze hydrological changes, we use SMOS L1C data. A mounted microwave imaging radiometer with aperture synthesis (MIRAS) receives upward radiation at a frequency of $1.41 \mathrm{GHz}$. Maximum dependence of radiometer bandwidth on the incidence angle falls on $\theta \sim 42.5^{\circ}$; transverse spatial resolution is $35 \mathrm{~km}$, longitudinal one $65 \mathrm{~km}$ [32]. The L1C SMOS product contains brightness temperature $\left(T_{\mathrm{B}}\right)$ values on horizontal $\left(T_{B H}\right)$ and vertical $\left(T_{B V}\right)$ polarizations measured in the range of $0 \ldots 60^{\circ}$ [33]. L1C data are presented as the discrete geodetic grid DGG ISEA 4H9. The linear cell size is 16 $\mathrm{km}$, the area is approximately $195 \mathrm{~km}^{2}[34]$.

In this study, we use $\mathrm{T}_{\mathrm{BH}}$ from L1C corresponding to $42.5^{\circ}$. To ensure maximum reliability, the following initial data are excluded from the analysis: 1) burdened by the influence of radio frequency interference (according to RFI1 quality flag); 2) received outside Alias Free region, free from overlapping replica (AF quality flag); 3 ) with an error of $\mathrm{T}_{\mathrm{BH}}$ greater than $\left.5 \mathrm{~K} ; 4\right)$ with a polarization coefficient $\left(T_{B H} / T_{B V}\right)$ out of range from 0.01 to 0.99 . Spatial distribution of $T_{B H}$ is compared with MODIS satellite images obtained for the same territory (https://worldview.earthdata.nasa.gov ).

Data from Landsat, Sentinel satellites (optical range) were used to plot the DGG ISEA $4 \mathrm{H} 9$ grid and SMOS satellite data. The combination of three arrays of satellite data in optical, infrared, and microwave ranges made it possible to correlate brightness characteristics of the underlying surface with its specific areas. For test sites with homogeneous underlying surface, we determined seasonal dynamics of JD and identified characteristic periods of changes in microwave radiation of the underlying surface. (JD - Julian day, counted from 01.01.2012). On the basis of the long-term seasonal dynamics of JD, the shifts in dates of drastic changes in emissivity as well as the duration of the identified 
periods were determined and then used in assessing time shifts during the periods of wetland freezing / thawing.

\section{Results and Discussion}

Seasonal dynamics of brightness temperatures $T_{\mathrm{B}}(\mathrm{JD})$ of the underlying surface of wetlands varies greatly depending on their geographical location, climatic and natural zones. Emissivity characteristics of the underlying surface depend on

- soil moisture, salinity and temperature (for soil cover);

- water temperature and salinity (for water surface);

- biomass and vegetation phenology (for vegetation);

- temperature, biomass and phenology, living (e.g., moss) or dead (peat) vegetation (for marsh vegetation).

At subzero temperatures, a seasonally frozen layer appears on the soil surface, whereas ice cover - on the water surface. In this case, wetlands emissivity is up to the ratio between the frozen layer thickness and the skin layer depending on microwave wavelength and dielectric characteristics of various skin layers. For instance, Figures 1 and 2 show seasonal dynamics of $T_{\mathrm{B}}(\mathrm{JD})$ on vertical and horizontal polarizations for the world's largest tropical wetlands Pantanal (South America) and Sudd (Africa). During the year, the area of the Pantanal varies from 150 (drought) to 195 th. $\mathrm{km}^{2}$ (rainy season). Figure 1a-b) demonstrates seasonal dependencies of $T_{\mathrm{B}}(\mathrm{JD})$ for two seasons, i.e., dry winter and wet summer ones. During the latter, the Pantanal turns into a huge lake-swamp. Figure1a-b gives dependencies of $T_{\mathrm{B}}(\mathrm{JD})$ for cells DGG ID 1239786 and 1243886, while 1c-d - satellite images in the visible range (Google Earth).

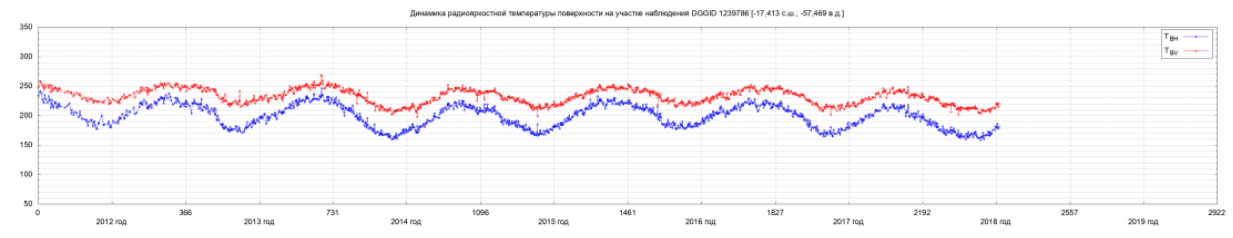

a)

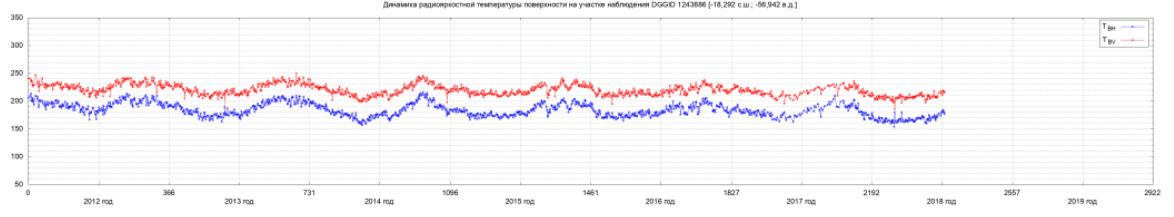

b)

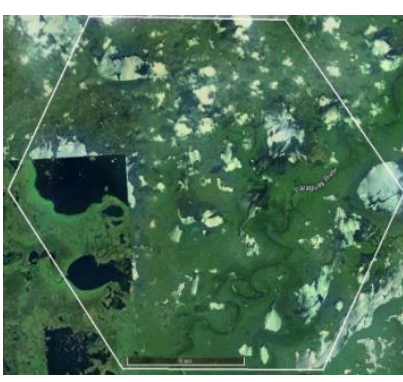

c)

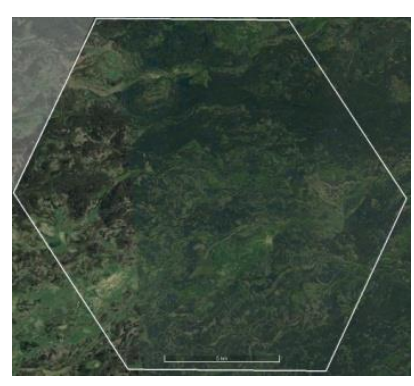

d)

Figure 1. Long-term dependencies of $T_{\mathrm{B}}(\mathrm{JD})$ for the Pantalan swamp (South America): cells DGG ID 1239786 (a), 1243886 (b) and their satellite images (c, d).

The area of the Sudd wetlands (Africa) varies as 30 (drought) - 150 th. $\mathrm{km}^{2}$ (rainy season). Figure 2 presents long-term dependencies of $T_{B}(J D)$ for the Sudd (Africa): cells DGG ID 2192443 (a), 2193466 (b) and their satellite images (c, d). 
The results of satellite monitoring of these world's largest wetlands indicate that $T_{\mathrm{B}}(\mathrm{JD})$ depends on the duration of tropical rainy seasons and droughts as well as on the rate of drying up and moistening of the territory during changes in seasons and vegetation phenology. The analysis of long-term dynamics of $T_{\mathrm{B}}(\mathrm{JD})$ for both wetlands suggests no evident changes in $T_{\mathrm{B}}(\mathrm{JD})$ that points to stability of hydrological processes of moistening and drying up in these wetlands, at least during the study period.

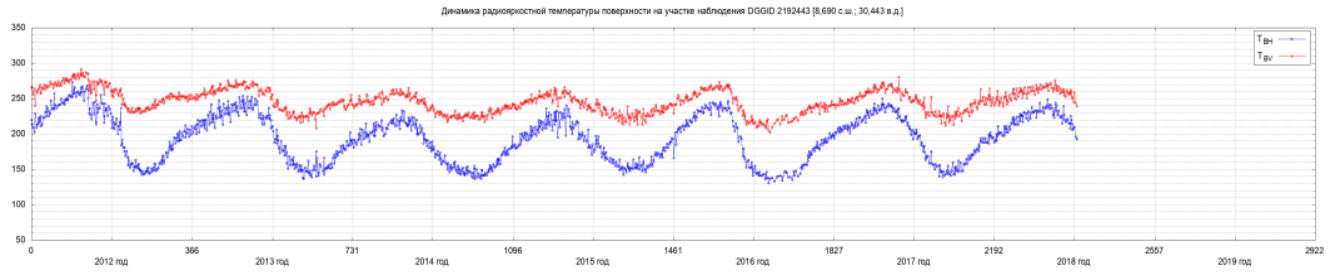

a)

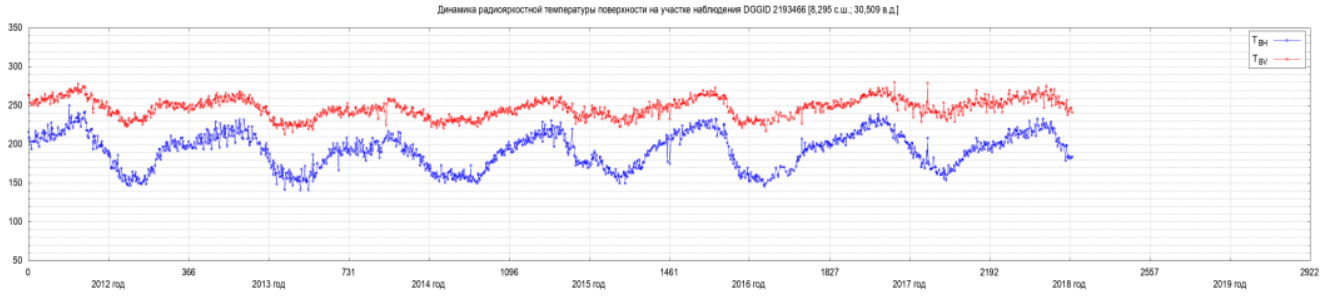

b)

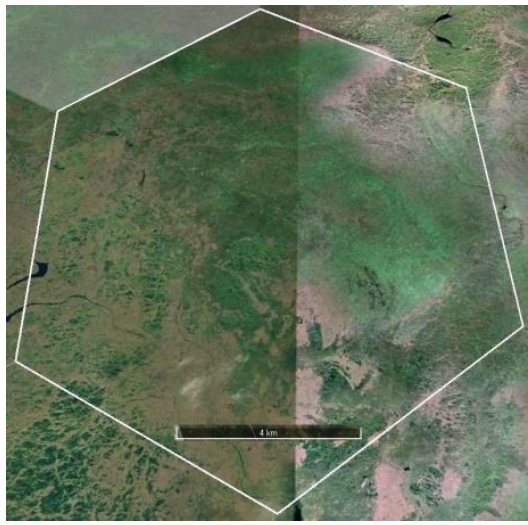

c)

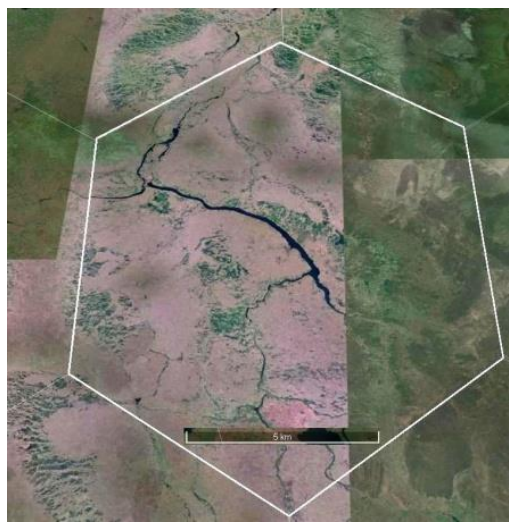

d)

Figure 2. Long-term dependencies of $T_{B}(J D)$ for the Sudd swamp (Africa): cells DGG ID 1239786 (a), 1243886 (b) and their satellite images (c, d).

Wetlands of the taiga zone

In contrast to tropical wetlands, seasonal dynamics of Western Siberia swamps located in the temperate zone depends not only on the type of underlying surface (swamp, vegetation cover, peat bogs), but also on intensity of seasonal freezing in swamp thickness and rates of formation and growth of ice cover on the water surface. The Vasyugan Swamp $\left(53\right.$ th. $\left.\mathrm{km}^{2}\right)$ located on the territory of the Vasyugan plain in the interfluve of the $\mathrm{Ob}$ and Irtysh rivers in the taiga zone is the largest in Western Siberia and among world's largest wetlands. Figure $3 \mathrm{a}-\mathrm{b}$ shows dependences of $T_{\mathrm{B}}(\mathrm{JD})$ for test sites with vast forest areas, including waterlogged ones falling into the pixel of the satellite radiometer. According to graphs analysis, long-term seasonal dynamics of $T_{\mathrm{B}}(\mathrm{JD})$ remains constant. The observed differences may be related to vegetation cycles of grass and woody plants, primarily, yellowing and falling of leaves that makes forest canopy radio-transparent and ceases the underlying surface shielding (waterlogged soil, in particular). 


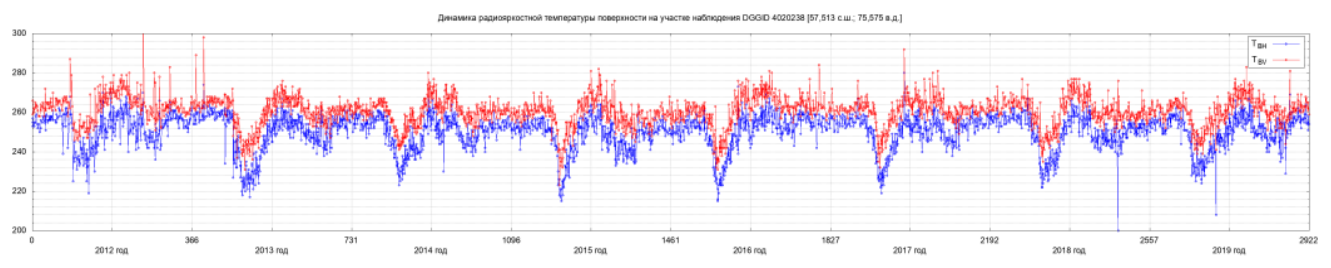

a)

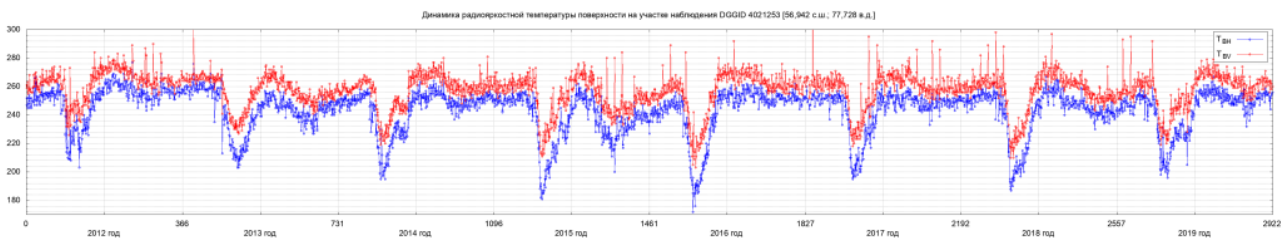

b)

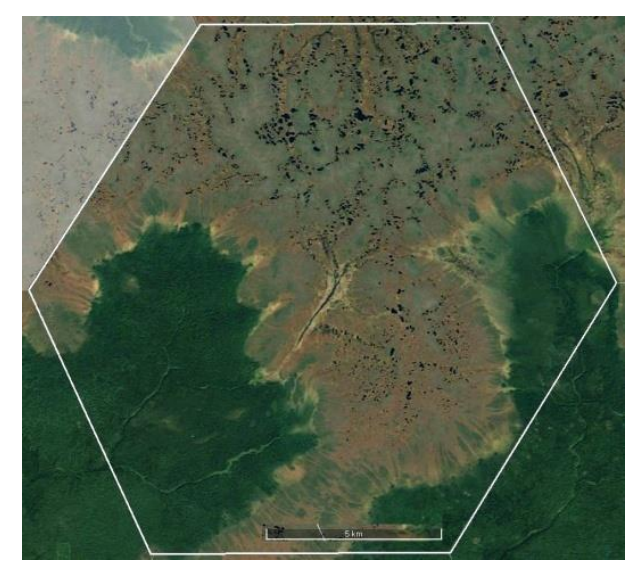

c)

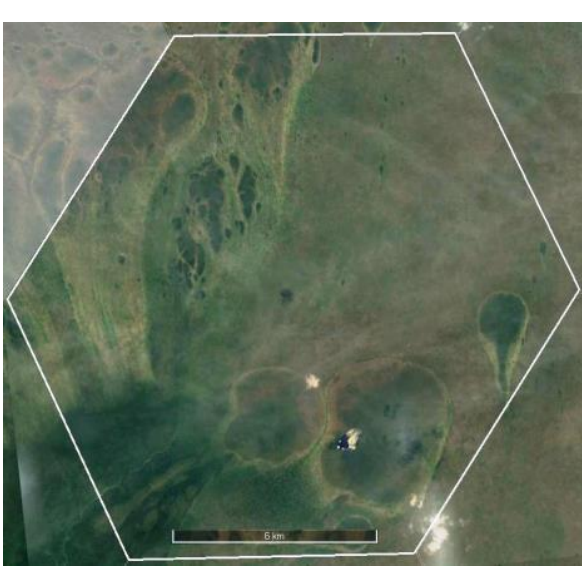

d)

Figure 3. Long-term dependencies of $T_{\mathrm{B}}(\mathrm{JD})$ for test sites of the Vasyugan Swamp (Western Siberia, Russian Federation): cells DGG ID 4020238 (a)(Vasyugan), 4021253 (b)(Ostyatsk) and their satellite images (c, d).

Figure 4a-b shows long-term seasonal dependences of $T_{\mathrm{B}}(\mathrm{JD})$ for swampy test areas of the northern taiga (Khanty-Mansi Autonomous Okrug, Western Siberia, Russian Federation): cells DGG ID 4019774 (a), 4021820 (b) and their satellite images (c, d). In contrast to southern wetlands, in the northern ones the proportion of coniferous evergreens is greater than that of deciduous trees. Less forested areas also exist (see Fig. 4b). In this case, $T_{B}(J D)$ depends on the type of surface and underwater marsh vegetation, its biomass and phenological processes associated with the growth and withering of vegetation cover, including seasonal processes of drying out/watering of the territory.

By the example of the Mukhrino swamp, the following five periods for bogs and wetlands of the northern taiga were identified (Fig. 5):

1) 1-2 "Winter" plateau - a period approximately from the beginning of November to the end of March when $\mathrm{T}=255 \mathrm{~K}$ values are constant (within confidence intervals) or show a weakly expressed positive trend.

2) 2-3 "Spring melting" - a rapid (10-30 days) "decline" of $T_{\mathrm{B}}(\mathrm{JD})$ up to $220 \mathrm{~K}$ induced, probably, by water covering a large part of the underlying surface due to melting of a seasonal snow cover. As a rule, minimum values of $T_{B}(\mathrm{JD})$ are noted less than for 2-5 days, i.e., a negative dynamic is promptly replaced by a positive one. $T_{\mathrm{B}}(\mathrm{JD})$ growth is a bit slower and not monotonous in all cases. 
3) 3-4 "Summer period 1" - in various years, dynamics of $T_{B}(J D)$ differs. It depends on vegetation cycles of marsh plants. Point 4 demonstrates the maximum value of $T_{\mathrm{B}}(\mathrm{JD})$; it can correspond to the maximum drying of a wetland area or the maximum development of marsh vegetation and its shielding of the water surface.

4) 4-5 "Summer period 2" - vegetation withering.

5) 5-1 "Autumn-winter freezing" of the swamp stratum. The type of seasonal dynamics depends on freezing peculiarities of the swamp stratum as a multilayer system consisting of living and dead vegetation, soil, including dielectric characteristics of different types of marsh vegetation (living and dead) under varying temperature and moisture. As remote radiophysical criteria characterizing current hydrological changes in wetlands, one can use durations of periods

1) not frozen swamp stratum,

2) formation of a seasonally frozen layer (up to the skin layer thickness),

3) a seasonally frozen layer with a thickness greater than the skin layer. Long-term trends in the duration of these periods allow us to identify a climate change vector in these regions.

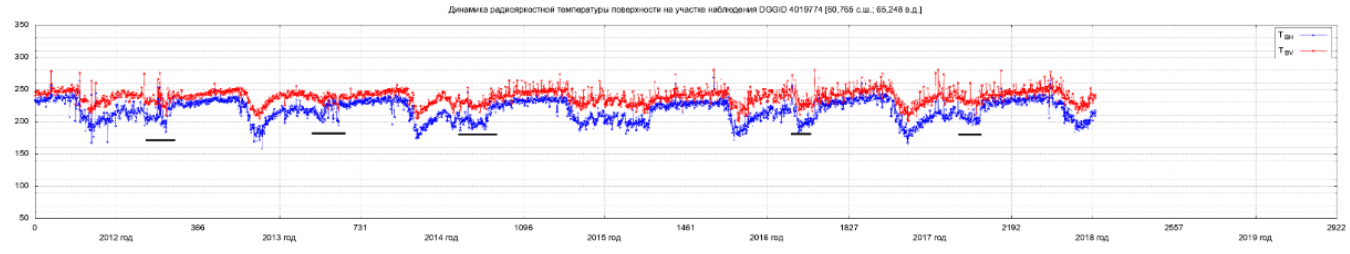

a)

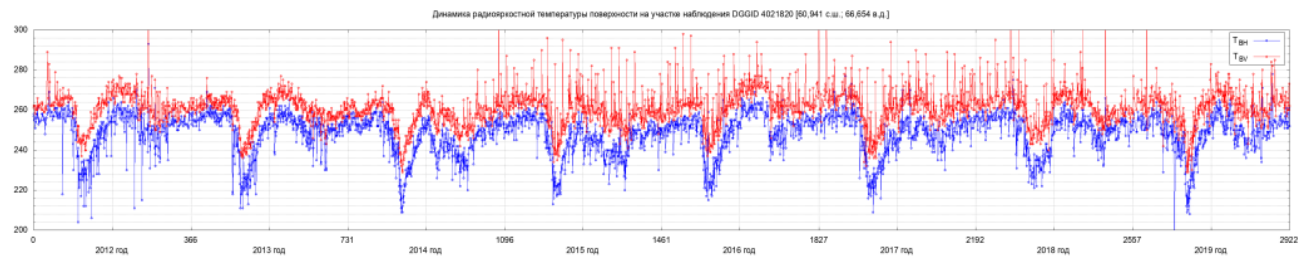

b)

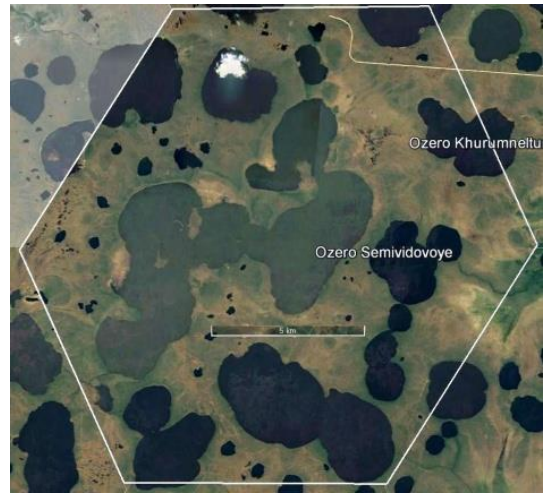

c)

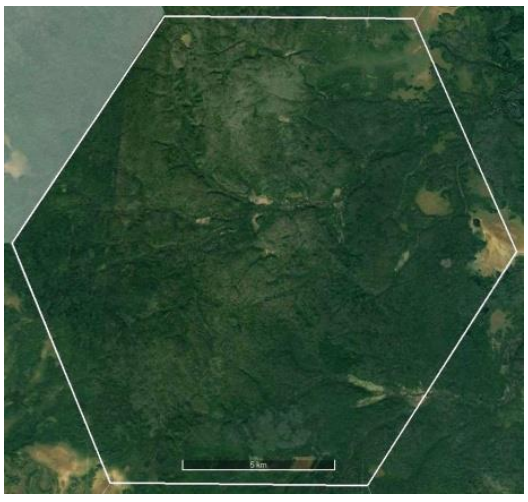

d)

Figure 4. Long-term dependences of $T_{B}(J D)$ for test sites of wetlands in the northern taiga (Khanty-Mansi Autonomous Okrug, Western Siberia, Russian Federation): cells DGG ID 4021820 (a), 4019774 (b) (Mukhrino swamp), and their satellite images (c, d). 


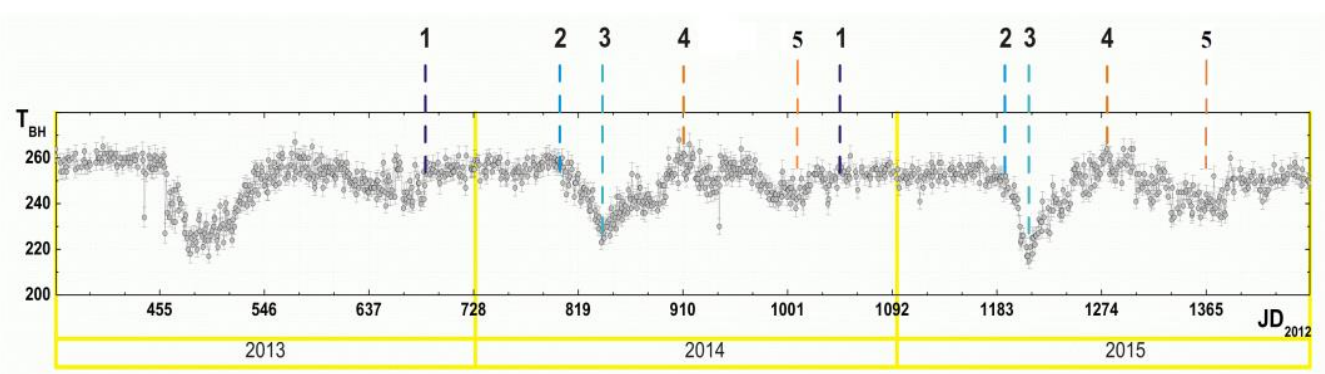

Figure 5. Variations of brightness temperatures of the underlying surface of wetlands.

\section{Wetlands of the Arctic and Subarctic}

Seasonal dynamics of brightness temperatures $T_{\mathrm{B}}(\mathrm{JD})$ of wetlands located in the Arctic and Subarctic zones was studied by the example of test sites in the Yamalo-Nenets Autonomous Okrug. Figure 6a presents a schematic map of test cells of the geodetic grid DGG ISEA 4H9. Figure 6b-c shows SMOS (product L1C) data for January and May. Small values of brightness temperatures (blue and black) correspond to open water or waterlogged areas. The satellite data analysis indicates that significant territories of the Yamal and Gydan peninsulas (YANAO) were severely flooded in spring because of intensive melting of a snow cover.

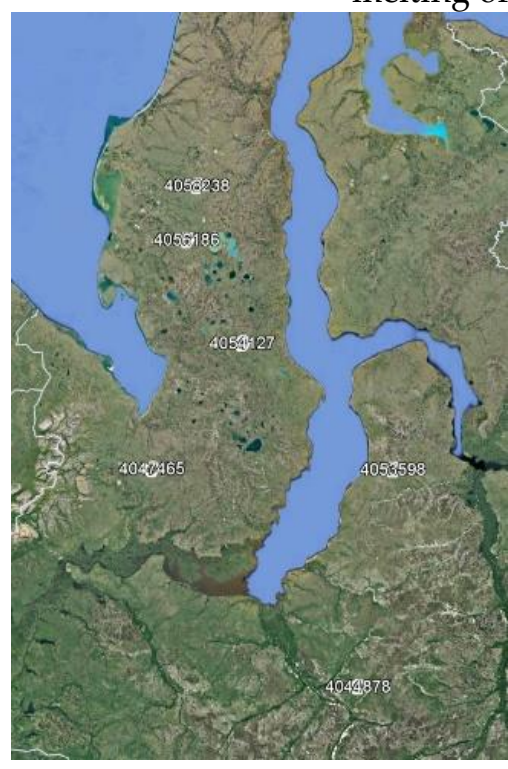

(a)

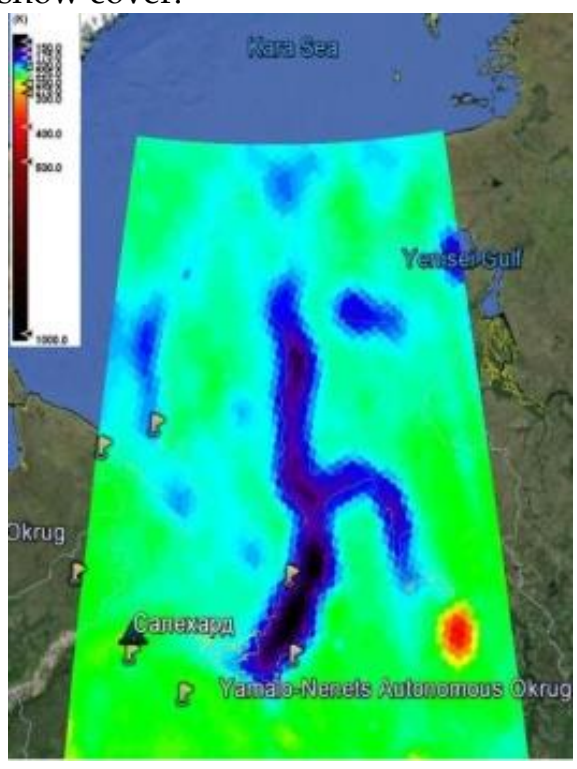

(b)

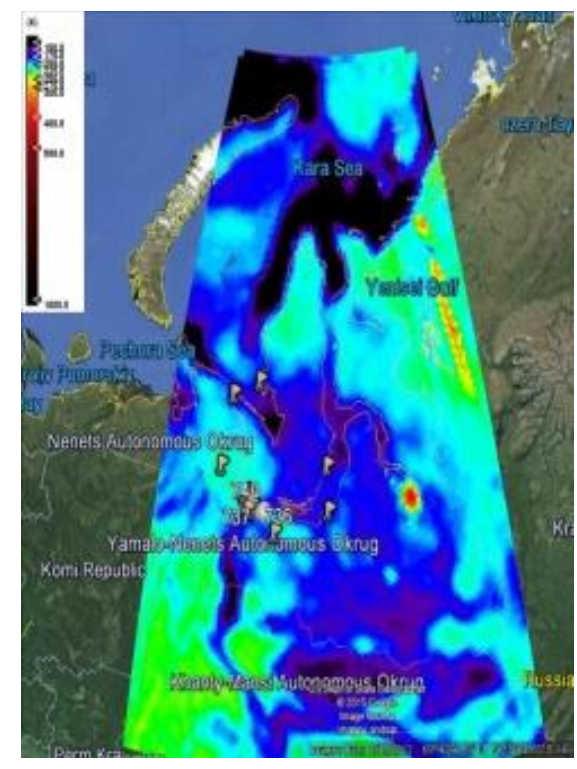

(c)

Figure 6. Schematic map of the Yamal-Nenets Autonomous District with specified test cells and SMOS data for January (b) and May (c)

Figure 7 (a-f) shows dependences of $T_{\mathrm{B}}(\mathrm{JD})$ for test sites marked in Fig. 6a. Seasonal dynamics of $T_{\mathrm{B}}(\mathrm{JD})$ in test sites $\mathrm{a}, \mathrm{b}, \mathrm{c}$, e are similar unlike the site located much farther to the south. Thus, $T_{\mathrm{B}}(\mathrm{JD})$ of wetland territories of the Arctic and Subarctic located at different latitudes vary. This may be due to different durations of cold and warm periods depending on geographical latitudes of the area as well as various rates of freezing and thawing of the upper layer of the underlying surface (waterlogged soil, open water). In contrast to more southern territories, the areas located beyond the Arctic Circle are characterized by the presence of permafrost. The analysis of $T_{\mathrm{B}}(\mathrm{JD})$ for the study sites made it possible to determine reliably the duration of cold periods for different years with an accuracy of up to a day. Durations of cold periods for the studied test areas were determined based on long-term seasonal dynamics of $T_{B}(J D)$ (see Fig. 8). For the tundra, as a multilayer system with a seasonally thawed upper layer, specific periods in seasonal 
dynamics of $T_{B}(J D)$ of the underlying surface associated with seasonal freezing of the upper layer were identified:

1) "winter" tundra" (without seasonally thawed layer) (a cold period);

2) seasonal thawing of the upper layer of permafrost soil;

3) "summer" tundra with seasonally thawed soil layer (warm period);

4) freezing of seasonally thawed upper layer to permafrost.

Cold period durations, depending on physical characteristics of the underlying surface and meteorological conditions, may serve as a remote radio-physical criterion. Long-term trends in cold period durations can be used in assessing hydrological and climatic changes of the territory. 


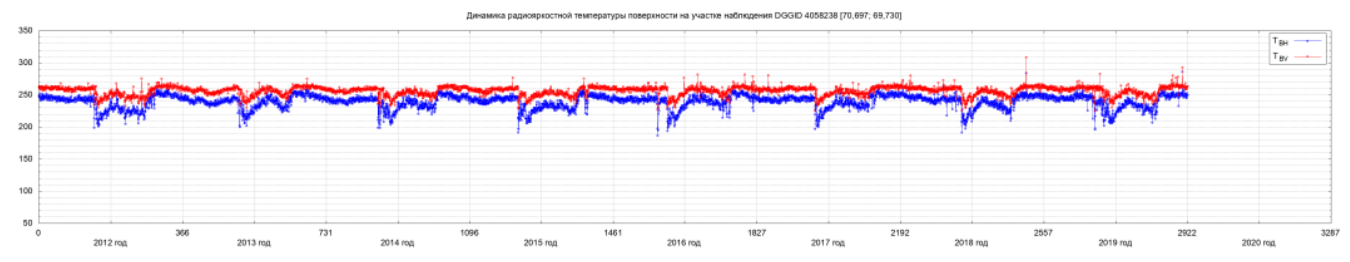

a)

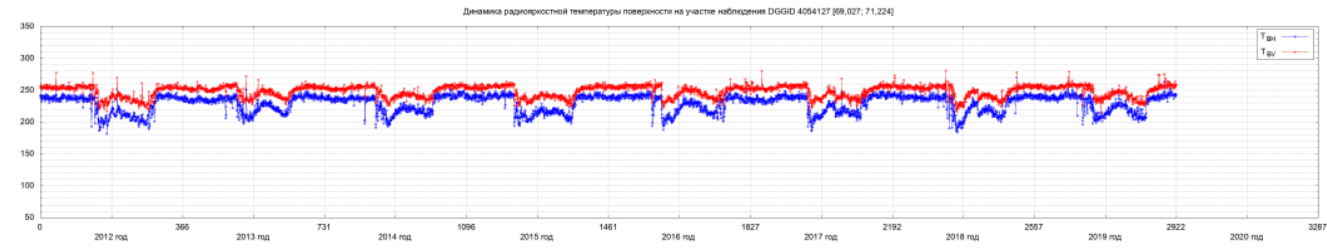

b)

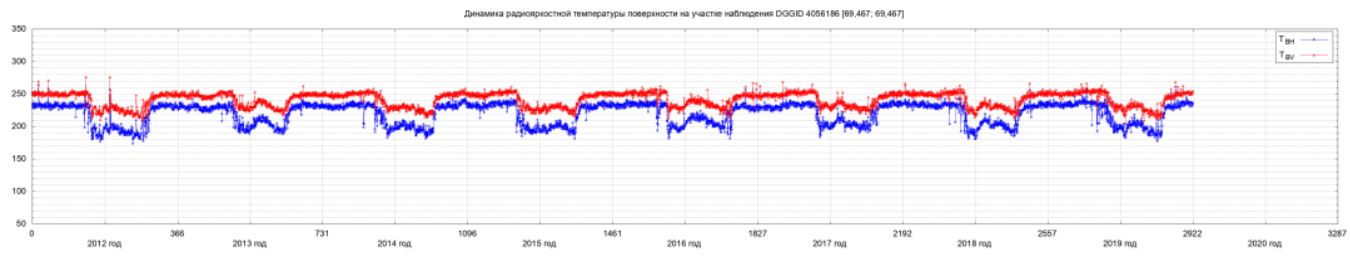

c)

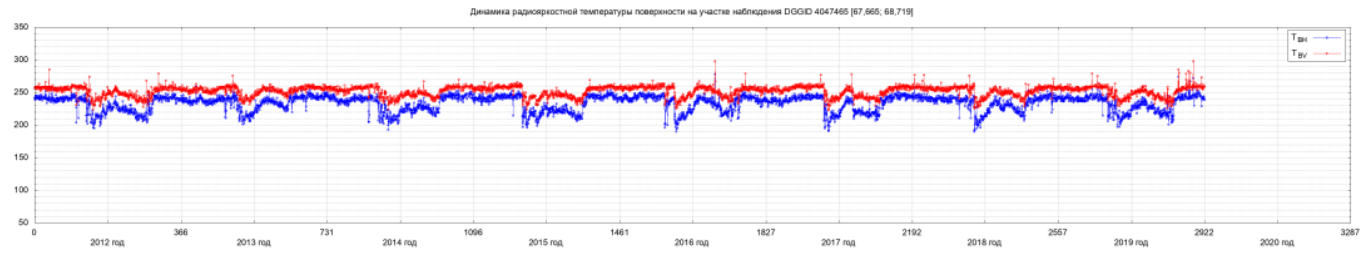

d)

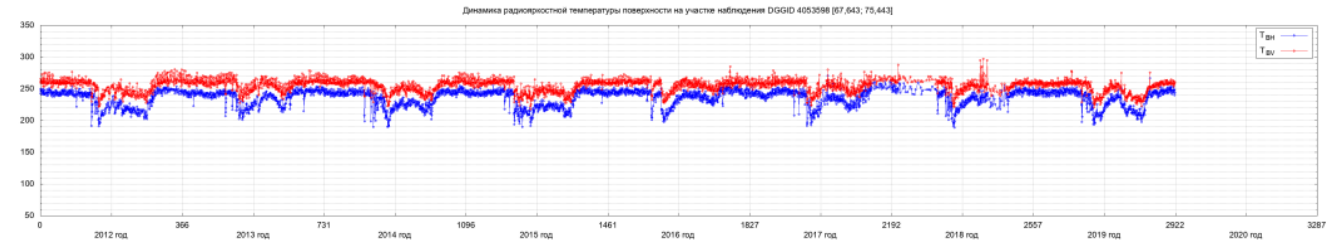

e)

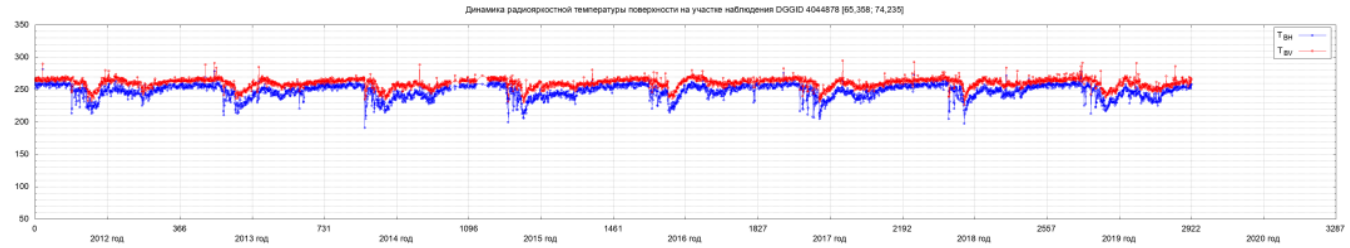

f)

Figure 7. Long-term seasonal dependences of TB (JD) for test sites marked in FIG. 6a: A - 4058238, b - 4054127, c - 4056878, d - 4047465, e - 4053598, f - 4044878. 


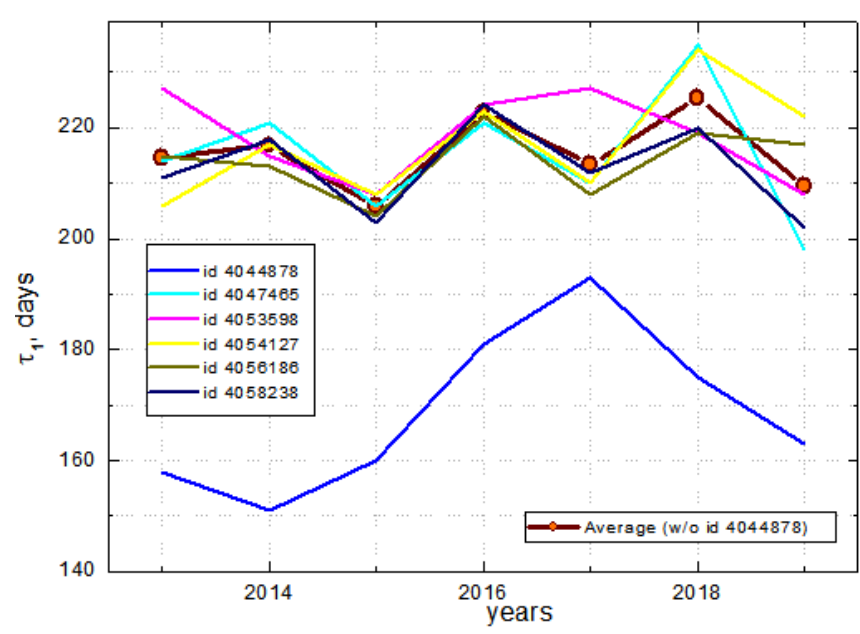

Figure 8. Interannual trends of cold period durations for test areas marked in Fig. 7.

\section{Conclusion}

The study results are evidence of some peculiar features of seasonal dynamics of brightness temperatures of wetlands, which significantly differ from those of the sea, freshwater lakes and seasonally frozen soils of the steppe zone. Perhaps it is due to specific freezing of the swamp stratum, which is a complex multi-layered multicomponent system consisting of waterlogged living and dead vegetation. Due to the analysis of SMOS satellite data, ground-based and laboratory measurements we revealed seasonal and long-term changes in wetland emissivity, which may be caused by hydrological and climatic changes.

Author Contributions: Conceptualization, Andrey Romanov and Evgeniy Sharkov; methodology, Andrey Romanov and Ilya Khvostov; software and validation, Ilya Khvostov and Vasiliy Tikhonov; data curation, Ilya Khvostov; writing - original draft preparation, Andrey Romanov and Ilya Khvostov; writing - review and editing, Andrey Romanov and Vasiliy Tikhonov; project administration, Andrey Romanov; funding acquisition, Vasiliy Tikhonov. All authors have read and agreed to the published version of the manuscript.

Acknowledgments: This study was carried out as a part of State Task of Institute for Water and Environmental Problems SB RAS, Space Research Institute RAS in the framework of the "Monitoring" State Research Theme (State Reg. No. 01.20.0.2.00164) with financial support of the RFBR project No. 20-05-00198-a.

Conflicts of Interest: The authors declare no conflict of interest.

\section{References}

1. Karlsson, J.M.; Jaramillo, F.; Destouni, G.; Hydro-climatic and lake change patterns in Arctic permafrost and non-permafrost areas. Journal of Hydrology 2015, Vol. 529, Part 1, pp. 134-145. doi.org/10.1016/j.jhydrol.2015.07.005

2. Bring, A.; Destouni, G.; Hydro-climatic changes and their monitoring in the Arctic: Observation-model comparisons and prioritization options for monitoring development. Journal of Hydrology 2013, Vol. 492, pp. 273-280. doi.org/10.1016/j.jhydrol.2015.07.005

3. Koven, C.D.; Riley, W.J.; Stern, A.; Analysis of permafrost thermal dynamics and response to climate change in the CMIP5 Earth system models. J. Clim. 2013, Vol. 26, pp. 1877-1900.

4. Bergamaschi, P.; Houweling, S.; Segers, A.; et al.; Atmospheric CH4 in the first decade of the 21st century: inverse modeling analysis using SCIAMACHY satellite retrievals and NOAA surface measurements. J. Geophys. Res. Atmos. 2013, Vol. 118, pp. 7350-7369.

5. Poursanidis, D.; Chrysoulakis, N.; Remote Sensing, natural hazards and the contribution of ESA Sentinels Missions. Remote Sensing Applications: Society and Environment 2017, Vol. 6, pp. 25-38. http://dx.doi.org/10.1016/j.rsase.2017.02.001

6. McCulloch, M.E.; Spurgeon, P.; Chuprin, A.; Have mid-latitude ocean rain-lenses been seen by the SMOS satellite? Ocean Modelling, 2012, Vol. 43-44, pp. 108-111. doi:10.1016/j.ocemod.2011.12.005

7. Santi, E.; Paloscia, S.; Pettinato, S.; Fontanelli, G.; Application of artificial neural networks for the soil moisture retrieval from active and passive microwave spaceborne sensors. International Journal of Applied Earth Observation and Geoinformation 2016, Vol. 48, pp. 61-73. DOI: 10.1016/j.jag.2015.08.002 
8. Tikhonov, V.V.; Repina, I.A.; Raev, M.D.; Sharkov, E.A.; Ivanov, V.V.; Boyarskii, D.A.; Alexeeva, T.A.; Komarova, N.Y.; A physical algorithm to measure sea ice concentration from passive microwave remote sensing data. Advances in Space Research 2015, Vol. 56, 1578.

9. Mirmazloumi, S.M.; Moghimi, A.; Ranjgar, B.; Mohseni, F.; Ghorbanian, A.; Ahmadi, S.A.; Amani, M.; Brisco, B. Status and Trends of Wetland Studies in Canada Using Remote Sensing Technology with a Focus on Wetland Classification: A Bibliographic Analysis. Remote Sens. 2021, 13, 4025. https://doi.org/10.3390/rs13204025

10. Brisco, B.; Ahern, F.; Murnaghan, K.; White, L.; Canisus, F.; Lancaster, P.; Seasonal Change in Wetland Coherence as an Aid to Wetland Monitoring. Remote sensing 2017, Vol. 9. Issue2. Article Number158. Feb. 2017. DOI10.3390/rs9020158

11. Adeli, S.; Salehi, B.; Mahdianpari, M.; Quackenbush, L.J.; Brisco, B.; Tamiminia, H.; Shaw, S. Wetland Monitoring Using SAR Data: A Meta-Analysis and Comprehensive Review. Remote Sens. 2020, 12, 2190. https://doi.org/10.3390/rs12142190

12. Olthof, I.; Rainville, T.; Evaluating Simulated RADARSAT Constellation Mission (RCM) Compact Polarimetry for Open-Water and Flooded-Vegetation Wetland Mapping. Remote Sens. 2020, Vol. 12, 1476; doi:10.3390/rs12091476

13. Chen, Z.; White, L.; Banks, S.; Behnamian, A.; Montpetit, B.; Pasher, J.; Duffe, J.; Bernard, D.; Characterizing marsh wetlands in the Great Lakes Basin with C-band InSAR observations. Remote Sensing of Environment 2020. Vol. 242, 111750. https://doi.org/10.1016/j.rse.2020.111750.

14. Endo, Y.; Halabisky, M.; Moskal, L.M.; Koshimura, S. Wetland Surface Water Detection from Multipath SAR Images Using Gaussian Process-Based Temporal Interpolation. Remote Sens. 2020, 12, 1756. https://doi.org/10.3390/rs12111756

15. Huth, J.; Gessner, U.; Klein, I.; Yesou, H.; Lai, X.; Oppelt, N.; Kuenzer, C. Analyzing Water Dynamics Based on Sentinel-1 Time Series - a Study for Dongting Lake Wetlands in China. Remote Sens. 2020, 12, 1761. https://doi.org/10.3390/rs12111761

16. Battaglia, M.J.; Banks, S.; Behnamian, A.; Bourgeau-Chavez, L.; Brisco, B.; Corcoran, J.; Chen, Z.; Huberty, B.; Klassen, J.; Knight, J.; Morin, P.; Murnaghan, K.; Pelletier, K.; White, L. Multi-Source EO for Dynamic Wetland Mapping and Monitoring in the Great Lakes Basin. Remote Sens. 2021, 13, 599. https://doi.org/10.3390/rs13040599

17. Crowson, M.; Warren-Thomas, E.; Hill, J.K.; et al.; A comparison of satellite remote sensing data fusion methods to map peat swamp forest loss in Sumatra, Indonesia. Remote sensing in ecology and conservation 2019, Vol. 5. Issue 3, pp. 247-258. DOI:10.1002/rse2.1025 (3)

18. Yu, G.N.; Liu, D.C.; Zhou, H.M.; Zen, L.X.; Zhong, Y.F.; Zhang, C.; Automated identification of swamp land incorporating Landsat TM image and GIS data. In Book Hyperspectral remote sensing and applications Edited by Green, R.O.; Tong, Q.; Book Series Proceedings of the society of photo-optical instrumentation engineers (SPIE). 1998, Vol. 3502, pp. 267-269. DOI: 10.1117/12.317801.

19. Li, Z.W.; Wang, Z.Y.; Brierley, G.; Nicoll, T.; Pan, B.Z.; \& Li, Y.F.; Shrinkage of the Ruoergai Swamp and changes to landscape connectivity, Qinghai-Tibet Plateau. Catena 2014, 126, pp. 155-163. https://doi.org/10.1016/j.catena.2014.10.035

20. Dabrowska-Zielinska, K,; Gruszczynska, M,; Lewinski, S,; Hoscilo, A,; Bojanowski, J.; Application of remote and in situ information to the management of wetlands in Poland. J. Environ Manage 2009, Vol. 90(7): 2261-9. DOI: 10.1016/j.jenvman.2008.02.009. Epub 2008 Apr 18. PMID: 18423845.

21. Elmes, M.C.; Davidson, S.J.; Price, J.S.; Ecohydrological interactions in a boreal fen-swamp complex, Alberta, Canada. Ecohydrology 2021, Article Number: e2335.

22. Jamali. A.; Mahdianpari, M.; Brisco B., et al. Deep Forest classifier for wetland mapping using the combination of Sentinel-1 and Sentinel-2 data. Giscience \& remote sensing 2021, DOI: 10.1080/15481603.2021.1965399.

23. Betbeder, J.; Gond, V.; Frappart, F.; et al. Mapping of Central Africa Forested Wetlands Using Remote Sensing. IEEE Journal of selected topics in applied earth observations and remote sensing 2014, Vol.7, Issue2, pp.531-542 . DOI: 10.1109/JSTARS.2013.2269733

24. White, E.; Kaplan, D.; Identifying the effects of chronic saltwater intrusion in coastal floodplain swamps using remote sensing. Remote sensing of environment 2021, Vol. 258. Article Number112385. DOI10.1016/j.rse.2021.112385.].

25. Juman, R.A.; Ramsewak, D.; Land cover changes in the Caroni Swamp Ramsar Site, Trinidad (1942 and 2007): implications for management. Journal of coastal conservation 2013, Vol. 17. Issue1 , pp..133-141 DOI:10.1007/s11852-012-0225-0

26. Yu R.H.; Liu T.X.; Li Z.J.; Shang, M.H.; Seasonal Variation in the Area of Wuliangsuhai Wetland. Advanced Research in Aerospace, Robotics, Manufacturing Systems, Mechanical Engineering and Bioengineering, 2013, Vol. 295-298, Issue 3, pp. 1963 1967. DOI: 10.4028/www.scientific.net/AMM.295-298.1963

27. Jenkins, R.B.; Frazier, P.S.; High-Resolution Remote Sensing of Upland Swamp Boundaries and Vegetation for Baseline Mapping and Monitoring. Wetlands 2010, Vol. 30. Issue 3, pp. 531-540. DOI: 10.1007/s13157-010-0059-1

28. Choudhury, B.J. Passive microwave remote-sensing contribution to hydrological variables. Surveys in geophysics. 1991; Vol. 12, Issue1-3, pp. 63-84. https://doi.org/10.1007/BF01903412

29. Jensen, K.; McDonald, K.; Surface Water Microwave Product Series Version 3: A Near-Real Time and 25-Year Historical Global Inundated Area Fraction Time Series from Active and Passive Microwave Remote Sensing. IEEE Geoscience and remote sensing letters. 2019, Vol. 16. Issue 9, pp. 1402-1406. DOI: 10.1109/LGRS.2019.2898779

30. Schroeder, R.; McDonald, K.C.; Chapman, B.D.; Jensen, K.; Podest, E.; Tessler, Z.D.; Bohn, T.J.; Zimmermann, R. Development and Evaluation of a Multi-Year Fractional Surface Water Data Set Derived from Active/Passive Microwave Remote Sensing Data. Remote Sens. 2015, 7, 16688-16732. https://doi.org/10.3390/rs71215843

31. Mialon A. Wetland seasonal dynamics and interannual variability over northern high latitudes, derived from microwave satellite data. Journal of geophysical research 2005, Vol. 110, D17102, doi:10.1029/2004JD005697

32. Y. H. Kerr, et al., "The SMOS Mission: New Tool for Monitoring Key Elements of the Global Water Cycle”, Proceedings of IEEE 2010, Vol. 98, Issie. 5, pp. 666-687. DOI: 10.1109/JPROC.2010.2043032 
33. Gutierrez, A.; Castro, R.; Vieira, P.; SMOS L1 Processor L1c Data Processing Model. SO-DS-DME-L1OP-0009. No. 2.14, 2014, 80 p., available at: https://earth.esa.int/documents/10174/1854456/SMOS_L1c-Data-Processing- Models.

34. Sahr, K.; White, D.; Kimerling, A.J.; Geodesic Discrete Global Grid Systems. Cartography and Geographic Information Science 2003, Vol. 30, Issue 2, pp. 121-134.

35. Microwave Remote Sensing-Active and Passive. By F. T. Ulaby. R. K. Moore and A. K. Fung. (Reading, Massachusetts: Addison-Wesley, 1981 and 1982). Volume I: Microwave Remote Sensing Fundamentals and Radiometry. P. 473. 